\title{
Oxygen supplementation targets in patients with acute respiratory failure
}

\author{
Kenneth Nugent MD, Gilbert Berdine MD
}

\begin{abstract}
Many critically ill patients require oxygen supplementation, but the best level of support remains uncertain. The trade-off involves adequate oxygen delivery to tissues versus oxygen toxicity, which can result in adverse outcomes. The target level of support often involves measurement of either the $\mathrm{PaO}_{2}$ or the peripheral $\mathrm{O}_{2}$ saturation with a goal of $60 \mathrm{mmHg}$ for $\mathrm{PaO}_{2}$ and $90 \%$ for $\mathrm{O}_{2}$ saturation. This level of support typically places the patient on the plateau region of the hemoglobin-oxygen dissociation curve with the argument that additional increments in $\mathrm{PaO}_{2}$ or $\mathrm{O}_{2}$ saturation provide little additional $\mathrm{O}_{2}$ content.

Potential adverse effects of hyperoxia include formation of reactive oxygen species that can cause direct tissue injury, disruption of surfactant function, and absorptive atelectasis in regions along with low VQ ratios. ${ }^{1-3}$ These latter regions may contribute to the development of atelectrauma and additional lung injury. The New England Journal of Medicine recently published two randomized control trials that compared conservative oxygen supplementation versus a liberal or usual oxygen supplementation.
\end{abstract}

The ICU-ROX (Intensive Care Unit Randomized Trial Comparing Two Approaches to Oxygen Therapy) trial investigators randomized 1000 adult patients who were expected to require mechanical ventilation beyond the initial day of recruitment to either conservative or usual oxygen therapy. ${ }^{4}$ In both groups the default limit for the lower $\mathrm{O}_{2}$ saturation was $90 \%$; in the conservative oxygen group the upper limit of peripheral $\mathrm{O}_{2}$ saturation target was $97 \%$. If the patients in the conservative group maintained adequate $\mathrm{O}_{2}$ saturations, then the $\mathrm{FiO}_{2}$ could be reduced as low as 0.21 . The number of days of mechanical ventilation in survivors was approximately 3 in both groups. The

Corresponding author: Kenneth Nugent Contact Information: Kenneth.nugent@ttuhsc.edu DOI: 10.12746/swrccc.v8i34.671 primary outcome was the number of ventilator-free days from randomization until day 28 , and there was no difference between the 2 groups. The mean duration of ventilator-free days was 21.3 days in the conservative group and 22.1 days in the usual care group. The conservative care group spent more time at an $\mathrm{FiO}_{2}$ of 0.21 (median 29 hours) than the usual care group ( 1 hour) and spent less time with $\mathrm{O}_{2}$ saturations exceeding $96 \%$ than the usual care group (27 hours vs. 49 hours). Mortality rates at 90 and 180 days were similar. These investigators concluded that conservative oxygen therapy did not significantly affect the number of ventilator-free days and presumably did not reduce any potential adverse effects of oxygen on lung function and mechanics or on systemic tissues.

The $\mathrm{LOCO}_{2}$ (Liberal Oxygenation versus Conservative Oxygenation in Acute Respiratory Distress Syndrome) trial investigators randomized patients with ARDS to a conservative oxygen therapy target or to a liberal oxygen therapy target. ${ }^{5}$ The conservative target was $\mathrm{a} \mathrm{PaO}_{2}$ of 55 to $70 \mathrm{mmHg}$ and $\mathrm{O}_{2}$ saturations of 88 to $92 \%$. The liberal target was a $\mathrm{PaO}_{2} 90$ to $105 \mathrm{mmHg}$ and $\mathrm{O}_{2}$ saturations $\geq 96 \%$. This study initially planned to include 850 patients, but the trial was stopped after the recruitment of 205 patients due to safety concerns. Initial baseline characteristics of the patients included respiratory system compliance of approximately $30 \mathrm{ml} / \mathrm{cm} \mathrm{H}_{2} \mathrm{O}$ and $\mathrm{PaO}_{2} / \mathrm{FiO}_{2}$ ratios of $117-120$. Most patients $(71 \%)$ required catecholamine support. There were definite differences in the $\mathrm{FiO}_{2}, \mathrm{PaO}_{2}$, and $\mathrm{O}_{2}$ saturation between the 2 groups over 7 days. After day 1 , the $\mathrm{FiO}_{2}$ was approximately $40 \%$ in the conservative oxygenation group and $55 \%$ in the liberal oxygenation group. There was no difference in mortality at 28 days, but there was an increase in mortality in the conservative oxygen cohort at 90 days. Five patients in the conservative oxygen therapy group had mesenteric ischemia events, but details about these patients were not provided. These investigators concluded that a conservative oxygen 
therapy with a goal target goal of 55 to $70 \mathrm{mmHg}$ did not increase survival at 28 days. Potential hazards associated with lower targets included intermittent hypoxemia and possibly decreased $\mathrm{O}_{2}$ delivery to tissue beds with lower perfusion.

van den Boom et al reviewed two large databases to determine, if possible, optimal oxygen saturation targets in critically ill patients. ${ }^{6}$ This study included 26,723 patients from an ICU collaborative research database and 8,564 patients from a medical information mart for intensive care database. Patients were included if they had at least 48 hours of oxygen therapy and 24 pulse oximetry $\mathrm{O}_{2}$ saturation measurements. The investigators analyzed the median $\mathrm{O}_{2}$ saturations and their association with hospital mortality. These results had a U-shaped distribution, and the optimum median $\mathrm{O}_{2}$ saturation was in the range of 94 to $98 \%$. There was increased mortality below $94 \%$ and increased mortality above $98 \%$. The mortality increased with the percent time spent outside the optimal range. These results were adjusted for age, gender, BMI, the sequential organ failure score (SOFA) on admission, and the duration of oxygen therapy.

Other studies have reported adverse outcomes associated with hyperoxemia. Page et al retrospectively reviewed the outcomes of patients intubated for mechanical ventilation in an emergency department. ${ }^{7}$ This study focused only on the $\mathrm{PaO}_{2} \mathrm{~s}$ in the emergency department and required patients to have normoxia $\left(\mathrm{PaO}_{2} 60\right.$ to $\left.120 \mathrm{mmHg}\right)$ during the first day in the ICU. Three hundred and fifty patients had normoxia in the emergency department, and 300 had hyperoxia (i.e., a $\mathrm{PaO}_{2}>120 \mathrm{mmHg}$ ). Time spent in the emergency department was approximately 5.5 hours. After adjustment for multiple variables, they determined that hyperoxia in the emergency department was associated with increased mortality; the overall mortality rate was $29.7 \%$ in the hyperoxia group and $19.4 \%$ in the normoxia group. There was a gradient effect with increasing levels of hyperoxia resulting in increased mortality.

Asfar and colleagues studied hyperoxia and hypertonic saline in patients with septic shock using a $2 \times 2$ factorial randomized clinical trial. ${ }^{8}$ The oxygen management strategy involved either an $\mathrm{FiO}_{2}$ of 1.0 for the first 24 hours or an $\mathrm{FiO}_{2}$ set to target hemoglobin oxygen saturation at 88 to $95 \%$. This trial was stopped prematurely for safety reasons after 442 patients had been recruited. At 28 days and 90 days an increased number of patients in the hyperoxia group had died, but this did not reach statistical significance. There was an increased number of total adverse events during this study in the hyperoxia group and an increased number of patients with atelectasis. There is a trend towards an increased frequency of ICU acquired weakness in the hyperoxia cohort. This study was reanalyzed using a Sepsis-3 criteria for septic shock. ${ }^{9}$ Patients in the hyperoxia group with septic shock requiring vasopressors who had lactate levels greater than $2 \mathrm{mmol} / \mathrm{L}$ had higher mortality at 28 days ( $57.4 \%$ versus $44.3 \%, P=0.054$ ). Multivariate analysis of these results indicated that there was an independent association between hyperoxia and mortality at 28 days and 90 days in patients with septic shock with high lactate levels.

In summary, a retrospective review of a very large database suggested that the optimal $\mathrm{O}_{2}$ saturation in critically ill patients requiring $\mathrm{O}_{2}$ supplementation was 94 to $98 \%$. Two randomized controlled trials did not find any benefit in patients who had a lower upper limit of peripheral O2 saturation (97\%) to limit hyperoxemia or a target $\mathrm{PaO}_{2}$ of 55 to $70 \mathrm{mmHg}$. These studies suggest that oxygen supplementation targets should include $\mathrm{O}_{2}$ saturations greater than $94 \%$ and less than $98 \%$. However, other a relatively large studies demonstrated that hyperoxia in the emergency department during the initial phase of mechanical ventilation and hyperoxia for the first 24 hours of mechanical ventilation resulted in increased mortality. These results lead to some uncertainty as to the best strategy for oxygen supplementation in critically ill patients.

Correlation does not imply causation. There are plausible reasons why patients with high $\mathrm{O}_{2}$ saturation might do worse that do not involve $\mathrm{O}_{2}$ toxicity. High $\mathrm{O}_{2}$ saturation might be due to infrequent attention to clinical status. Patients with high $\mathrm{O}_{2}$ saturation might require greater levels of $\mathrm{O}_{2}$ support which may indicate a higher acuity or severity of disease irrespective of attempts to control for disease severity. Retrospective analyses and particularly meta-analyses may provide the basis for good hypotheses to be tested, but these hypotheses should be tested by prospective clinical trials designed to explicitly answer the question. 
Clinicians frequently do not know the stability of $\mathrm{O}_{2}$ saturation in critically ill patients, the frequency of low values, the frequency of high values, and the duration of either low or high values. In addition, clinicians usually do not know which organs have decreased perfusion and consequently are more vulnerable to low $\mathrm{O}_{2}$ saturations that might result in critical reductions in $\mathrm{O}_{2}$ delivery. Consequently, the management of oxygenation needs to be individualized according to the patient's clinical status and gas exchange, and there is no substitute for frequent reassessment of critically ill patients. Oxygen therapy probably needs more attention than it frequently receives in ICUs, given other critical care patient management responsibilities in ICUs. An $\mathrm{FiO}_{2}$ of 1.0 should be used for the shortest period of time possible. Hyperoxemia should be avoided in patients post cardiac arrest, in patients with CNS trauma, and in patients who are post stroke. ${ }^{10}$ The target of peripheral $\mathrm{O} 2$ saturation should exceed $90 \%$ and possibly be in the range of 94 to $98 \%$. Patients with low $\mathrm{O}_{2}$ saturations and high $\mathrm{FiO}_{2} \mathrm{~S}$ warrant extra concern and may need changes in management strategies, if possible.

Keywords: oxygen supplementation, ICU care, ARDS, $\mathrm{O}_{2}$ saturation, $\mathrm{FiO}_{2}$

From: The Department of Internal Medicine, Texas Tech University Health Sciences Center, Lubbock, Texas

Submitted: 3/24/2020

\section{REFERENCES}

1. Geoghegan P, Keane S, Martin-Loeches I. Change is in the air: dying to breathe oxygen in acute respiratory distress syndrome? J Thorac Dis 2018;10:S2133-S7.

2. Smallwood CD, Boloori-Zadeh P, Silva MR, et al. High oxygen concentrations adversely affect the performance of pulmonary surfactant. Respir Care 2017;62:1085-90.

3. Nugent K. Oxidative stress. The Southwest Respiratory and Critical Care Chronicles 2019:1-3.

4. Mackle D, Bellomo R, Bailey M, et al. Conservative oxygen therapy during mechanical ventilation in the ICU. N Engl J Med 2020;382:989-98.

5. Barrot L, Asfar P, Mauny F, et al. Liberal or conservative oxygen therapy for acute respiratory distress syndrome. N Engl J Med 2020;382:999-1008.

6. van den Boom W, Hoy M, Sankaran J, et al. The search for optimal oxygen saturation targets in critically ill patients: observational data from large ICU databases. Chest 2020; 157:566-73.

7. Page D, Ablordeppey E, Wessman BT, et al. Emergency department hyperoxia is associated with increased mortality in mechanically ventilated patients: a cohort study. Crit Care 2018;22:9

8. Asfar P, Schortgen F, Boisramé-Helms J, et al. Hyperoxia and hypertonic saline in patients with septic shock (HYPERS2S): a two-by-two factorial, multicentre, randomised, clinical trial. Lancet Respir Med 2017;5:180-90.

9. Demiselle J, Wepler M, Hartmann C, et al. Hyperoxia toxicity in septic shock patients according to the Sepsis-3 criteria: a post hoc analysis of the HYPER2S trial. Ann Intensive Care 2018;8:90.

10. Vincent JL, Taccone FS, He X. Harmful effects of hyperoxia in postcardiac arrest, sepsis, traumatic brain injury, or stroke: the importance of individualized oxygen therapy in critically ill patients. Can Respir J 2017;2017:2834956. 